Remote Sensing of Environment

August 2008, Volume 112, Issue 8, Pages 3329-3340

Earth Observations for Marine and Coastal Biodiversity and

Ecosystems Special Issue

http://dx.doi.org/10.1016/j.rse.2008.02.014

(c) 2008 Elsevier Inc. All rights reserved.
Archimer

Archive Institutionnelle de l'Ifremer http://www.ifremer.fr/docelec/

\title{
Towards a better assessment of the ecological status of coastal waters using satellite-derived chlorophyll-a concentrations
}

\author{
Francis Gohin ${ }^{a, ~}{ }^{\star}$, Bertrand Saulquin ${ }^{a}$, Héléne Oger-Jeanneret ${ }^{b}$, Loic Lozac' $h^{c}$, Luis Lampert ${ }^{d}$, \\ Alain Lefebvre ${ }^{\mathrm{e}}$, Philippe Riou ${ }^{\mathrm{d}}$ and Franck Bruchon ${ }^{\mathrm{f}}$
}

\footnotetext{
a Ifremer, Dynamique des Ecosystèmes Côtiers, BP 70, 29280 Plouzané, Brittany, France

b Ifremer Nantes Rue de l'Ile d'Yeu BP 2110544311 Nantes Cedex 3, Brittany, France

${ }^{\mathrm{c}}$ HOCER, 5 rue Bourdon, 29540, Guipavas, Brittany, France

d Ifremer Port-en-Bessin, Av. du Général de Gaulle, BP 32, 14520 Port-en-Bessin, France

e Ifremer Boulogne, 150 Quai Gambetta BP 699, 62321 Boulogne sur Mer Cedex, France

f Agence de l'Eau Seine-Normandie, Délégation au Littoral et à la Mer, 21 rue de I'Homme-de-Bois, 14600 Honfleur, France
}

*: Corresponding author : Gohin F., email address : Francis.Gohin@ifremer.fr

\begin{abstract}
:
The application of the new Water Framework Directive (WFD) of the European Union will require a dense and frequent monitoring of chlorophyll-a near the coast. Not counting the transitional water bodies located in the vicinity of estuaries, not less than seventy four coastal water bodies have to be monitored along the coast of the French Atlantic continental shelf and the English Channel. All the available data have to be gathered to implement a comprehensive monitoring scheme. To this purpose, we evaluate the capacity of ocean colour imagery to complete the conventional in situ data set collected in coastal networks. Satellite-derived chlorophyll-a concentration is obtained by the application of a coastal Look-Up-Table to water-leaving radiance of the Sea-viewing Wide Field Instrument Sensor (SeaWiFS) for the 1998-2004 period. Seven years of satellite-derived and in situ chlorophyll-a concentrations are compared at seven representative stations of different water bodies. These comparisons show that the satellite products are reliable in most of the situations studied and throughout the seasons. Then the satellite imagery is used to classify the coastal waters following the eutrophication risk criterion of the WFD. This classification is made according to the percentile-90 of chlorophyll-a calculated during the productive season, from March to October. Despite a lack of sensor coverage over a small fraction of the near shore waters, this work shows that the satellite monitoring can considerably ease the application of the WFD.
\end{abstract}

Keywords: Satellite; Chlorophyll; Monitoring; Surveillance; Coastal; SeaWiFS 


\section{Introduction}

Since the launch of SeaWiFS in September 1997, followed by MODIS/AQUA and MERIS in 2002, a huge set of ocean colour data has been collected on the coastal waters of the Bay of Biscay and the English Channel. Chlorophyll-a and mineral suspended particulate matter (SPM) are derived from satellite radiance by using a dedicated Look-Up-Table (Gohin et al., 2002; Gohin et al., 2005). Satellite-derived maps are now routinely provided to a large community of users through a web site (http://cersat.ifremer.fr/data/view/nausicaa/nausicaa_tutorial). Providing validation and calibration data to regional biogeochemical models is a major application of satellite remote sensing in these waters (Druon et al., 2005; Ménesguen and Gohin, 2006; Ménesguen et al., 2007; Lacroix et al., 2007). Mineral SPM derived from satellite data are also used to force the light availability at the end of winter in a biological model of the Bay of Biscay (Huret et al., 2006). Monospecific blooms are frequently observed from space. The species involved in these surface blooms are identified from their optical signatures or through in situ observations. Coccolithophores are regularly observed and identified from the whitish aspects of their surrounding waters in spring on the edge of the continental shelf of the Irish Sea, the Western English Channel (Smyth et al., 2002), and in the Bay of Biscay. A monospecific late winter bloom of Coscinodiscus wailesii has also been observed by SeaWiFS and identified from in situ measurements (Gohin et al., 2003). It has also been possible to monitor HABs (Harmful Algal Blooms), targeting a species (as Karenia mikimotoi) and a period (generally spring and summer) when conditions for remote observation are most favourable (Miller et al., 2006). However, these promising applications do not need the level of accuracy required by the water quality policies based today on in situ networks. The challenge of using chlorophyll-a concentrations derived from satellite water-leaving radiance in coastal waters to assess the long-term trends is double. First, scientists have to cope with an optically complex medium whose properties change dramatically throughout the seasons, considering both the atmosphere and the water. Second, they have to ensure the continuity of monitoring with an equivalent level of quality whatever the space sensor is.

In situ measurements have the considerable advantage of long term continuity and, although their reliability may also be questioned, they are the reference the satellite data have to conform to. To that purpose, the MarCoast project, a service element developed for the GMES (Global Monitoring for environment and Security) program of the European Union, promotes the coordinated use of both types of data and a closer cooperation between satellite data providers and observers working for conventional networks.

The need for an effective monitoring system of the coastal European waters considerably increased since the publication of the Directive 2000/60/EC of the European Parliament and of the Council establishing a framework for the Community action in the field of water policy (European Commission, 2000). In order to develop a common strategy for implementing the WFD, several guidance documents (European Communities, 2005) have been elaborated, and various thematic working groups have been set up. Among these, Geographical Intercalibration Groups (GiGs) work at identifying comparable tools and metrics for evaluating the ecological status of water bodies.

'Transitional waters' are defined by the WFD as bodies of surface waters which are substantially influenced by freshwater flows. 'Coastal waters' means surface waters on the landward side of a line, every point of which is at a distance of one nautical mile on the seaward side from the nearest point of the baseline from which the breadth of territorial waters is measured, extending where appropriate up to the outer limit of transitional waters. Coastal water bodies may therefore be very narrow, from the satellite point of view, except around the islands and in the bays. The boundaries of the water bodies of the Bay of Biscay and of the English Channel have been defined on the basis of hydrodynamical and sedimentary considerations (Lazure et al., 2002). Their physical homogeneity does not ensure an even distribution of the phytoplankton biomass and the sampling needed for the monitoring may require several stations at representative locations. Along the French Atlantic shore, seventy-four coastal water bodies and fifty-two transitional waters bodies have been defined.

The WFD classification scheme includes five categories for the ecological status: high, good, moderate, poor and bad. The general objective of the WFD is to achieve 'good status' for all surface waters by 2015. 'Good status' means both 'good ecological status' and 'good chemical status'. 'High status' is associated with no or very low human pressure. This is also called the 'reference condition' as it is the best status achievable. These reference conditions differ along the shores of Europe to take into account the diversity of the ecological regions. 
Quality assessment is a function of the deviation from the reference conditions, following the definitions of the Directive. 'Good status' means 'slight' deviation, 'moderate status' means 'moderate' deviation and so on. Several criterion are taken into account to define the ecological status of a water body. Amongst them, the eutrophication risk is assessed through the chlorophyll-a concentration, which is a proxy of phytoplankton biomass. Eutrophication was defined by Nixon (1995) as 'an increase in the rate of supply of organic matter to an ecosystem'. Its main cause is a high nutrient enrichment of water, especially nitrogen and/or phosphorus, enhancing phytoplankton growth. It can lead to a reduction of dissolved oxygen when the organic matter decomposes and to hypoxia in the extreme cases. Eutrophication produces an undesirable disturbance to the balance of organisms present in the water and to the quality of the water concerned. Thus, chlorophyll-a concentration, as a proxy of phytoplankton biomass, is a parameter that can be used to evaluate the efficiency of the actions taken to reduce anthropogenic enrichment in coastal waters.

The evaluation of the eutrophication risk of a water body will be established through the percentile $90, \mathrm{P} 90$, of the chlorophyll-a concentration integrated on its whole area. P90 represents the chlorophyll-a level such that $90 \%$ of the observations are equal to or less than this value.

As the satellite method enables the calculation of P90 pixel-by-pixel, P90 maps of chlorophyll-a can be created on the continental shelf. Therefore it is possible to expect, particularly for a wide water body, a better estimation of the mean P90, integrated over its area, than from isolated coastal stations. The relevance of the locations of some coastal stations, considered as representative of typical waters bodies, can also be evaluated from satellite imagery. This gives the method a unique advantage for the design of an optimised in situ network.

Before classifying the ecological status of coastal water bodies using satellite data, it is necessary to test their capacity to reproduce the statistical properties of the in situ data series. To that purpose, this study considers seven key stations along the coast and compares the time series of satellite and in situ chlorophyll-a concentrations for a seven year period, from 1998 to 2004. On a second step, satellite data are used to evaluate the ecological status of coastal water bodies for the eutrophication risk criterion.

\section{Data and methods}

\subsection{In situ data}

All the in situ data available from the main French monitoring networks were used for the final classification of the coastal water bodies. These observations were obtained from three networks: the REPHY phytoplankton network, the RNO (Réseau National d'Obervation) which is dedicated to the water quality, and the SOMLIT network managed by INSU (Institut National des Sciences de l'Univers). Seven stations along the shore have been selected for comparison with the time series of the SeaWiFS-derived chlorophyll-a concentrations during the period 1998-2004. These stations were selected for their capacity to represent specific regional water conditions along the shores of the southern English Channel and the French Atlantic continental shelf. They were also chosen because they have been frequently sampled in the recent years, through regional networks, as the SRN (Suivi Régional des Nutriments) and RHLN (Réseau Hydrologique Littoral Normand) funded by water agencies. Both networks contribute to Ifremer's REPHY network. The mean characteristics of the selected stations are presented in Table 1 and their locations are shown on Fig.1. One cross-shore transect, off Boulogne and belonging to the SRN network, is also considered as it reveals the chlorophyll-a gradient and can help to better understanding of the degradation of the quality of the satellite-derived products near the shore where pixels are often flagged (failure in the atmospheric correction, high radiance, etc.). This transect is the best sampled one available in the studied area. 


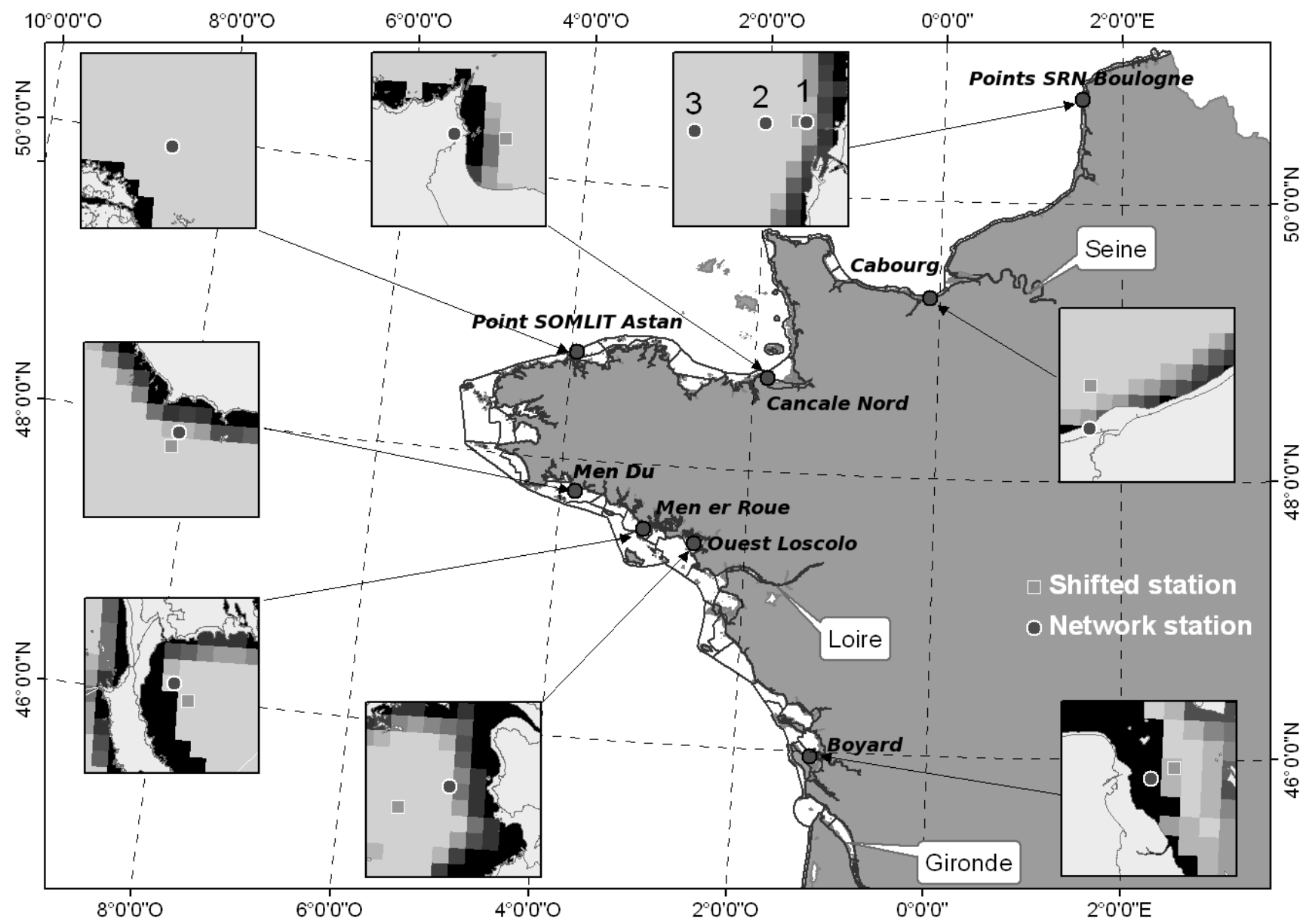

Fig.1 Locations of the studied stations and limits of the WFD water bodies. On the zoom, the pixels are coloured in black where there is no satellite observation and in light grey where the number of retrievals is greater than 100. Shades of grey are applied to values between the two extremes.

The concentration in chlorophyll-a was obtained by fluorometry or spectrophotometry. For spectrophotometric pigment analysis (Lorenzen, 1967; Aminot and Kerouel, 2004), 1 or 2 L surface seawater samples were prefiltered through $200 \mathrm{~mm}$ mesh nylon gauze and then filtered onto $47 \mathrm{~mm}$ GF/C fibre filters under low-pressure vacuum. The filters were ground into acetone-water solution $(90 / 10, \mathrm{v} / \mathrm{v})$ for pigment extraction and analysed by spectrophotometric method. The seawater volume filtered for the fluorimetric method (Neveux, 1976; Aminot and Kerouel, 2004) is lower than that used for the spectrophotometric method. 

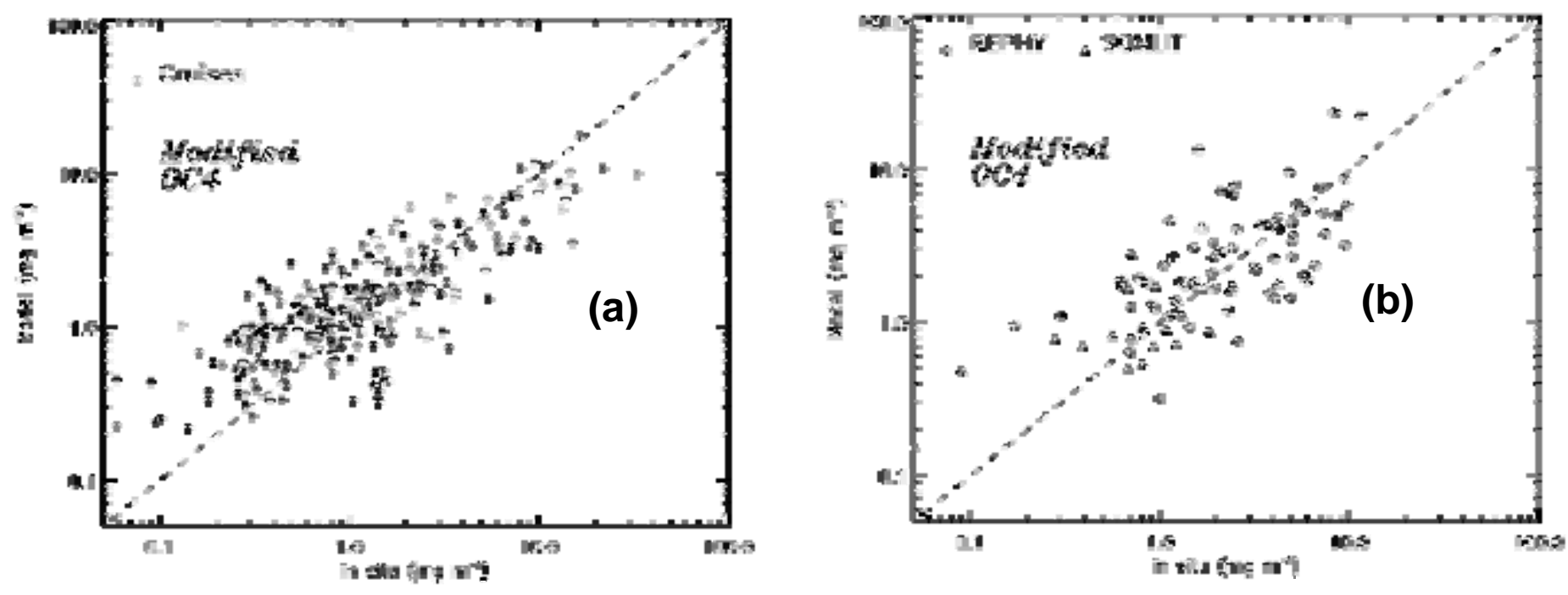

\subsection{Satellite data}

The SeaWiFS reflectance, or the normalised water-leaving radiance $\mathrm{nLw}$ from which it is derived, were used to estimate the chlorophyll-a concentrations. The reflectance at 412, 443, 490, 510 and $555 \mathrm{~nm}$ was obtained by applying the standard SeaWiFS processing chain SeaDAS 4.0 (Fu et al., 1998) to Level $1 \mathrm{~A}$ images (top of atmosphere radiance). Data were projected onto a regular grid in longitude $\left(0.015^{\circ}\right)$ and latitude $\left(0.01^{\circ}\right)$ allowing a spatial resolution of about $1.2^{\star} 1.2 \mathrm{~km}$. The standard SeaDAS cloud flag was applied. A uniformity test, based on the deviation of the pixel value compared to the local mean, was then applied to eliminate pixels close to the cloud-flagged areas. This empirical approach to retrieve the chlorophyll-a concentration is based on a Look-Up Table (LUT) which relates the SeaWiFS radiance to the chlorophyll-a concentration (Gohin et al., 2002). This method is derived from the OC4 algorithm (O'Reilly et al., 1998) as it is based on the same band ratios but corrections are added depending on the reflectance level in the 412 and $555 \mathrm{~nm}$ bands. The chlorophyll-a concentration obtained from the table is always lower than the value derived from OC4, which can be considered as an asymptotic solution for "clear" waters. The 412 band brings information on the atmospheric over-correction and the absorption by yellow substances whereas the 555 band is affected by the mineral particles. Overestimation of the atmospheric correction and mineral suspended matters often leads to a diminution of the reflectance ratio used in OC4 for coastal waters and consequently to an overestimation of the chlorophyll-a content by OC4 (Wozniak et Stramski, 2004; Gohin et al., 2005). The chlorophyll-a concentration is obtained by applying the LUT to triplets (OC4 maximum band ratio, nLw412, nLw555).

Fig. 2 shows the scatterplots of the satellite estimation versus in situ observation on the same day. In those comparisons, we have only considered point-to-point matches. Fig. 2a shows the scatterplots of the matches obtained from cruise data and Fig. $2 \mathrm{~b}$ from the SOMLIT and REPHY networks (including data from the associated RHLN and SRN networks). The cruise data set gathers 290 satellite-in situ pairs of data. This data set is an extension of the data already used for the calibration of the LUT in Gohin et al. (2002, 2005). The REPHY and SOMLIT data considered in this study were not used to that purpose. The correlation coefficient between cruise and satellite chlorophyll-a concentrations (log-transformed) is 0.79 . Fig. $2 b$ shows the scatterplots of 96 satellite-in situ chlorophyll-a concentration pairs. In that second case, the correlation coefficient decreases to 0.75 . A lower coefficient was expected as this data set, from the REPHY and SOMLIT networks, gathers coastal data at locations where the satellite technique is altered. Another feature visible on Fig. 2a, which is enhanced by the logarithmic scale, is the apparent overestimation of the chlorophyll-a concentration below $1 \mathrm{mg} \cdot \mathrm{m}^{-3}$ by the satellite method. This could be attributed to the LUT. However, it could also be related to the size of the sampling unit. The smaller the sampling unit is, the wider the histogram of the sample distribution is expected to be. Due to this effect, well known in geostatistics as the "support effect", the distributions of chlorophyll-a concentrations observed in situ through a volume unit of $0.5 \mathrm{~L}$, or by satellite through a volume unit in $10^{10} \mathrm{~L}$, could be different. The variance of chlorophyll-a concentrations observed from units of $10^{10} \mathrm{~L}$ 
(approximately the volume integrated over the area of a satellite pixel for an observed upper layer of seven meter depth) is expected to be significantly lower than that for a unit of $0.5 \mathrm{~L}$ (in situ). It is therefore expected that the most extreme measurements will be observed more frequently through in situ sampling and that their distribution would show a wider histogram than the satellite data. In coastal areas, currents and bathymetry create small scale chlorophyll-a features which can enhance the support effect. This effect will also have a direct consequence on the estimation of the chlorophyll-a P90 (P90) which is related to the variance. In a similar context, but in the field of air quality monitoring, Lajaunie and Wackernagel (2002) discuss in detail the expected effects of different sampling durations on the observed frequency of values over a critical level.

\subsection{Calculating time series of Chlorophyll-a statistics (mean and percentile 90) over fortnight intervals}

Seven years (1998-2004) of SeaWiFS and in situ chlorophyll-a concentrations have been used to build the time series at the selected stations. The mean and P90 are calculated on a 14 days (fortnight) basis. Mean chlorophyll-a contents over the fortnight $f$, $\mathrm{Chl}_{\mathrm{f}}(\mathrm{f})$, are calculated using:

$\mathrm{Chl}_{\mathrm{f}}(\mathrm{f})=\frac{1}{\mathrm{n}} \sum_{\mathrm{i}=1}^{\mathrm{n}} \mathrm{Chl}(\mathrm{i})$; with f from 1 to $26 \quad$ (1)

where $\mathrm{n}$ is the number of $\mathrm{Chl}$ observations measured in situ or derived from satellite observations for the fortnight $f$ and for any year from 1998 to 2004.

P90, which is defined as the level such that $90 \%$ of the observations are equal to or less than this value, is also calculated using the same fortnight temporal basis. A minimum of 3 values is required to calculate the fortnight mean and the P90. Percentile-p (here $p=0.9$ ) can be calculated whatever the number of observations (even less than 10) using the following method:

Let $X_{1}, X_{2}, X_{n}$ be the ordered values of $C h l$ and P-p the percentile we want to calculate.

We first calculate the product $n p$. This product can be split up between $j$ and $g$ where $j$ is the integer part of $n^{*} p$ and $\mathrm{g}$ is the decimal part.

$n$ : number of observations. $\quad n p=j+g$ where $j$ is the integer part of $n p$ and $g$ the decimal part.

P-p is given by the formula $\quad P-p=(1-g) X_{j}+g X_{j+1} \quad$ (2)

\subsection{Increasing the number of satellite-in situ matchups}

To match up in situ and satellite data, a point-to-point comparison is not systematically chosen because numerous in situ locations of the REPHY network are located near the shore where the water-leaving radiances of the satellite data are often flagged. For that reason, slightly offshore-shifted satellite observations are compared to field measurements in order to increase the number of matchups.

A detailed analysis of the satellite and in situ data series at the different stations allows a better assessment of the statistical deviation between both types of data. To that purpose, we used the SeaWiFS products archived at Ifremer. This data set contains only the best images, in term of cloud cover, for the period that ranges from January 1998 to March 2002. Since April 2002, the archive of daily data has been completed. It must also be noticed that the in situ sampling frequency was higher in the recent years as the regional networks (e.g. RHLN, SRN) were developed as pilot projects to prepare the new WFD monitoring program. Table 1 also presents the mean date of the in situ and satellite observations at the selected stations. The mean date generally occurs in 2002 and not in mid-2001 as it could be expected with a regular sampling. The recent mean date of the in situ measurements is related to the intensification of the monitoring along the last years. 


\subsection{The classification of the water bodies}

The chlorophyll-a status of a water body is classified as high/good/moderate/poor/bad with the respective P90 thresholds : $0-5,5-10,10-20,20-40,>40 \mathrm{mg} / \mathrm{m}^{3}$, calculated over its whole area and through the productive season which spans from March to October for the Atlantic coast of France (Fisson and Belin, 2005). The above thresholds are likely to be slightly modified by the North-East Atlantic GiG in a near future to ensure a continuity of the classification with the neighbouring countries (here Belgium and Spain). In most of the case the in situ classification of a water body is calculated from only one P90. Depending on the shape of the water body and on the mean distance to the coast, the satellite-based classification can be obtained from many more P90 and can be considered as more representative.

\section{Results}

\subsection{The time series of chlorophyll-a concentration at the selected stations}

The transect off Boulogne is very instructive. Although general conclusions cannot be drawn from this particular case, several aspects are interesting. The transect (Fig. 3) shows the typical gradient of increasing chlorophyll-a concentration towards the shore. The mean in situ chlorophyll-a concentrations are $8.8,6.1,3.8 \mathrm{mg} / \mathrm{m}^{3}$ for Point 1,2 , and 3 respectively. The satellite means at Point 2 and 3 are remarkably close to the corresponding in situ averages. Conversely, the satellite average of $6.1 \mathrm{mg} / \mathrm{m}^{3}$ at Point 1 , which is the closest station to the coast, is significantly lower than the in situ value. This agreement between the averages along the satellite and in situ transects is a little surprising if we consider that the sampled periods were significantly different. The data accounted for averaging are more recent (mean date in the second half of 2002) for the satellite-derived chlorophyll-a than for the in situ samples (second half of 2001).
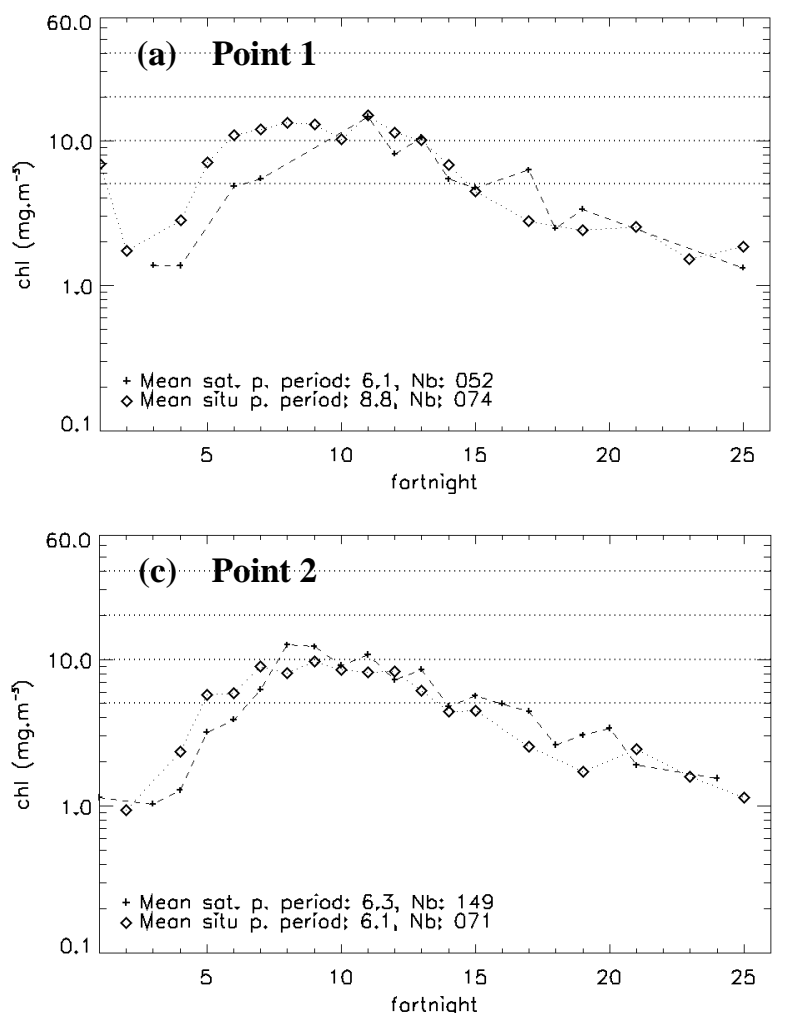
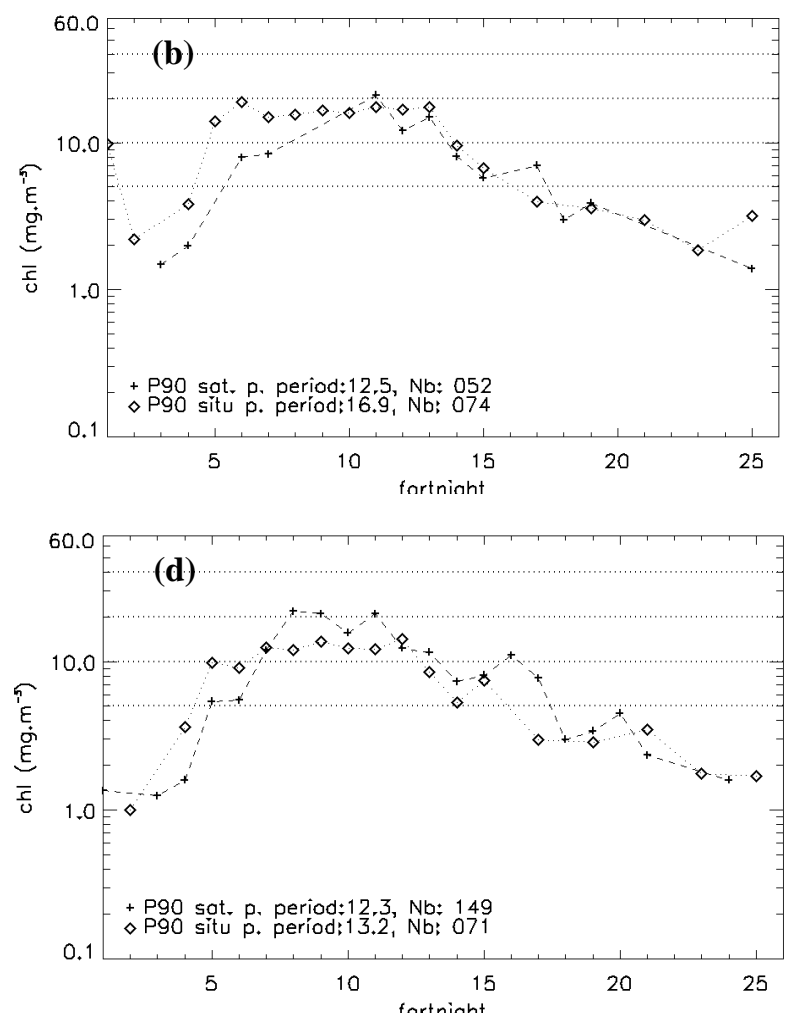

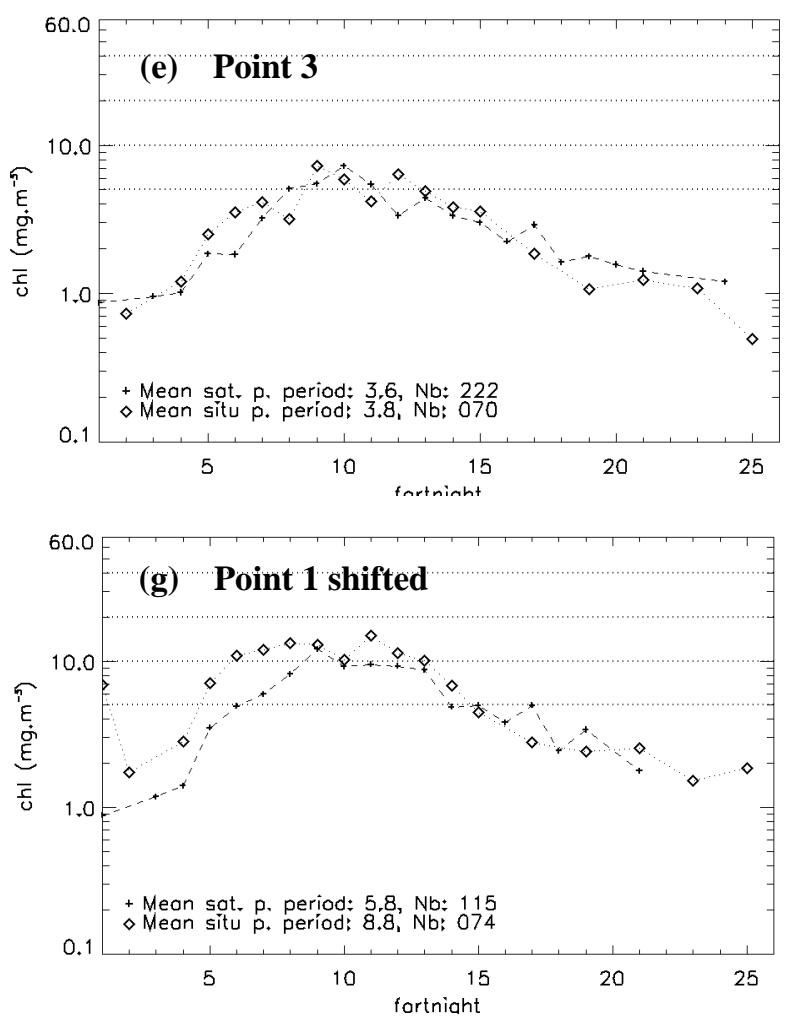
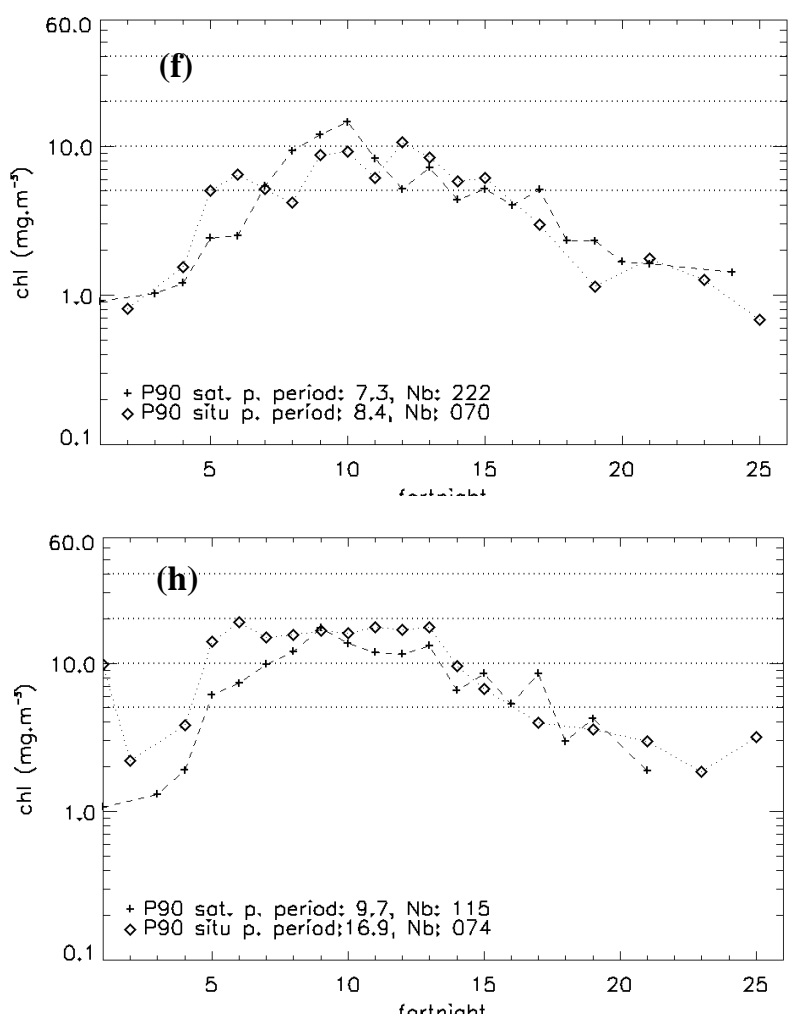

Fig.3. The annual cycles of the fortnight chlorophyll-a concentration (left) and percentile 90 (right) observed in situ and by remote sensing along the Boulogne transect. Threshold for the water quality levels (5; 10;20 and 40 $\mathrm{mg} \mathrm{m}^{-3}$ ) are indicated horizontally on the graphs.

The environmental conditions governing the phytoplankton growth are likely to be stable from one year to another in these well mixed coastal waters. The P90 levels are also very similar for Point 2 and 3 whatever the origin of the observations. Point 1 can help us to understand the poorer quality of the satellite estimation near the coast where difficulties inherent to the satellite processing often concur to flag the radiance. Whereas the numbers of available satellite data to calculate the average are 222 and 149 for Point 3 and 2, the number of satellite retrievals falls to 52 at Point 1 . By shifting Point 1 by one pixel $(1.2 \mathrm{~km})$ westwards (Fig. 1), the number of satellite data available for comparisons increases to 115.

Considering the other stations, two classes can be discriminated, based on the shape of their annual cycle. The river-influenced stations show a 'bell curve' as production is sustained by light and a high flux of nutrients all over the productive season. Cabourg, Ouest Loscollo and Boyard belong to that category. The others show a more typical spring peak followed by a decrease during the summer and autumn months. Satellite and in situ curves are very similar at all stations (Figs. 4-5). The largest difference in the P90 curves is observed at Cabourg where the in situ P90 is particularly high compared to the mean. The P90 to Mean ratio at that station is equal to 2.6 whereas it is close to 2.0 for the other stations.

The histograms of the satellite and in situ chlorophyll-a concentrations in clear (Roscoff Astan) and enriched waters (Cabourg) are shown on Fig. 6. In both cases, the satellite histograms are narrower than their in situ equivalent. This is also true for many stations along the coast (not shown). Although the LUT has probably an influence on the shape of the satellite histograms, the support effect could explain this situation. However the support effect does not seem to be significant in turbulent waters where the tidal cycle is strong and the underlying environmental conditions (nutrients, current, vertical structure,..) homogeneous. As expected from the support effect, the P90 to Mean ratio is lower when calculated from satellite data than from in situ measurements but the difference is low. The difference between the satellite (shifted 3 pixels offshore) and in situ averages at Cabourg can be greatly attributed to the shoreward chlorophyll-a gradient, as observed along the Boulogne's transect. At that location, the P90/average ratio, which is above 2, can also be related to a higher variability due to coastal microstructures at the scale of the pixel. 

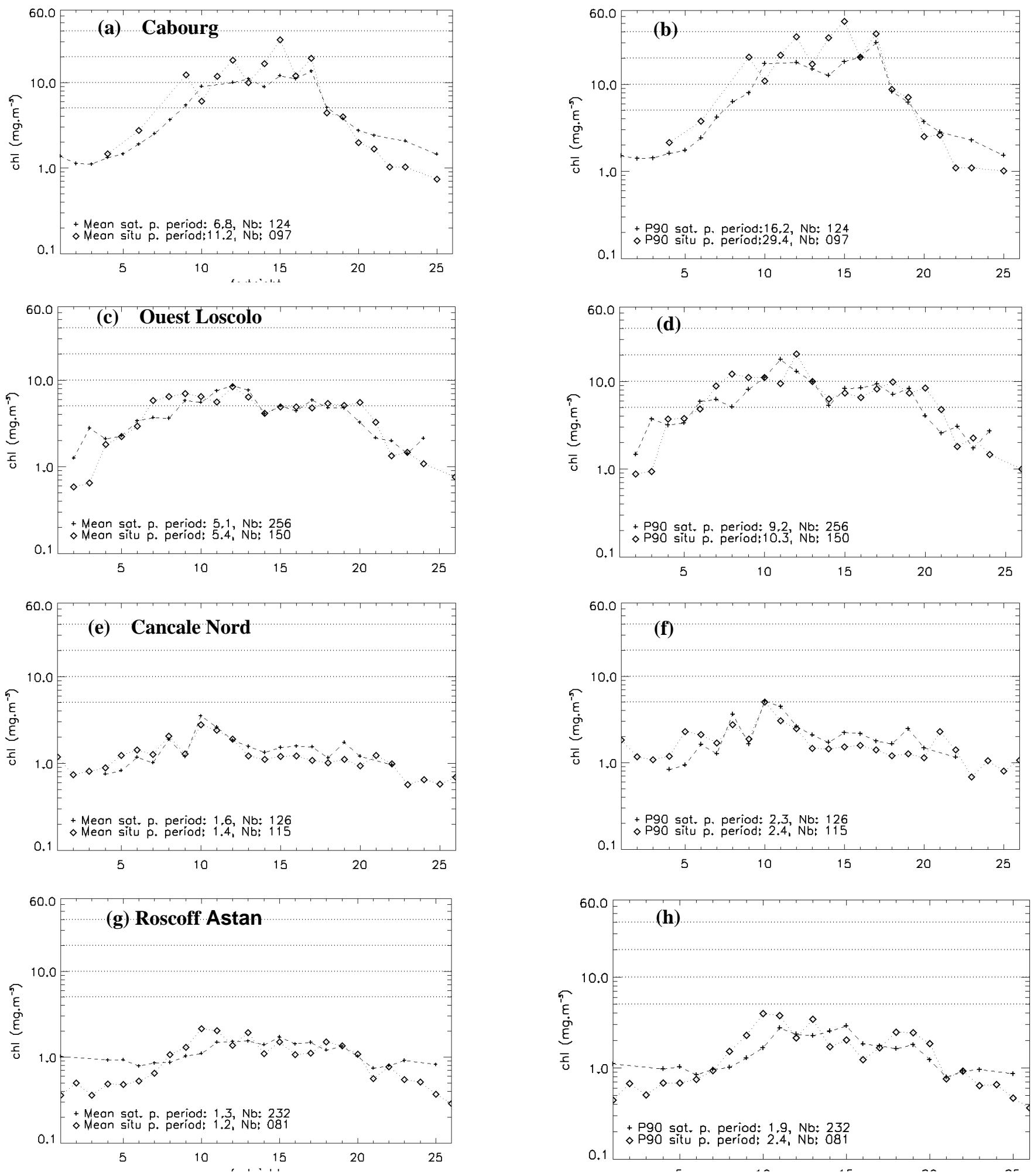

Fig.4. The annual cycles of the fortnight chlorophyll-a concentration (left) and percentile 90 (right) observed in situ and by remote sensing at Cabourg ( $a$ and b), Ouest Loscolo (c and d), Cancale (e and f), Roscoff ( $g$ and $h$ ). 

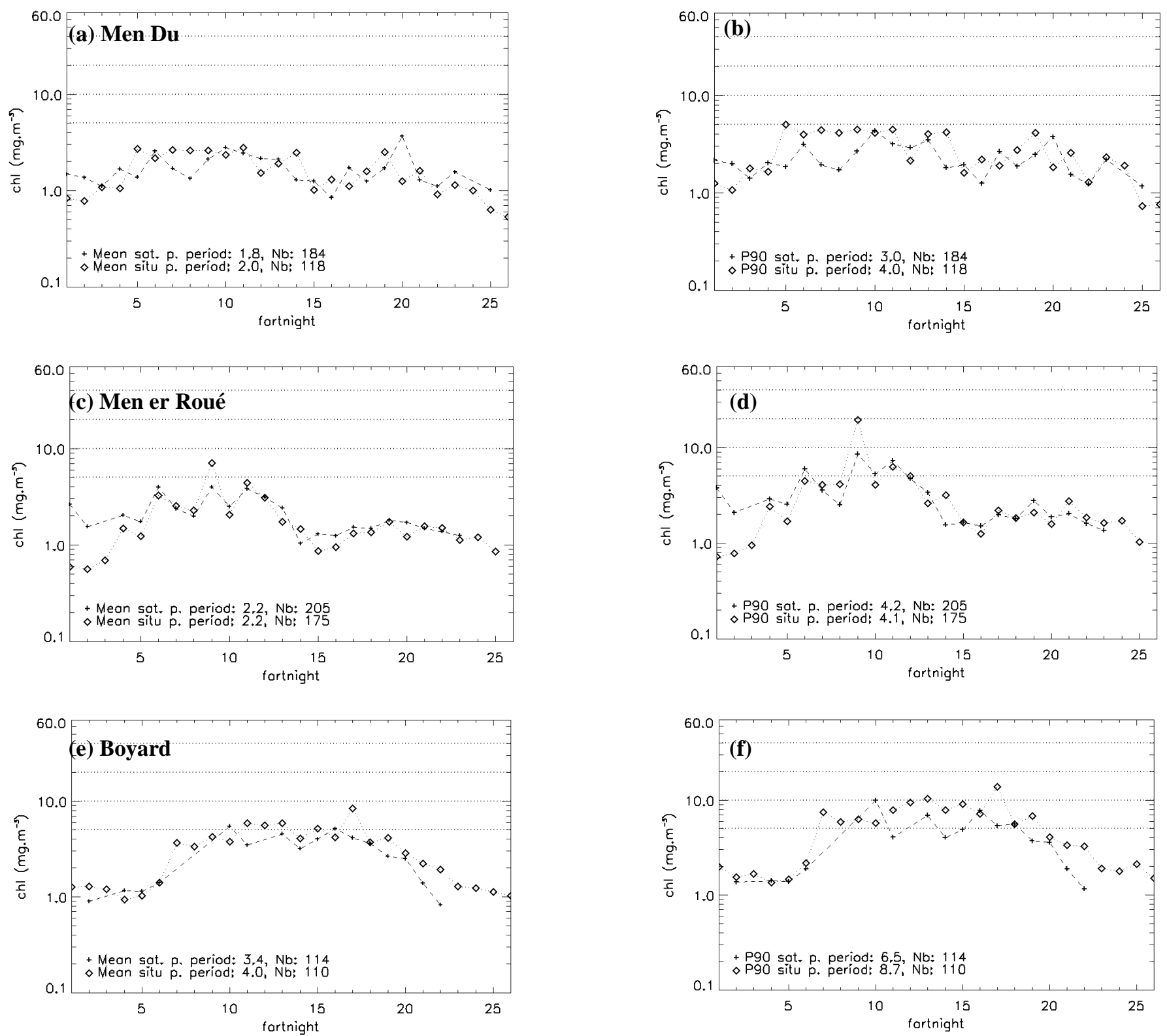

Fig.5. The annual cycles of the fortnight chlorophyll-a concentration (left) and percentile 90 (right) observed in situ and by remote sensing at Men Du ( $a$ and b), Men er Roué (c and d) and Boyard (e and f). 

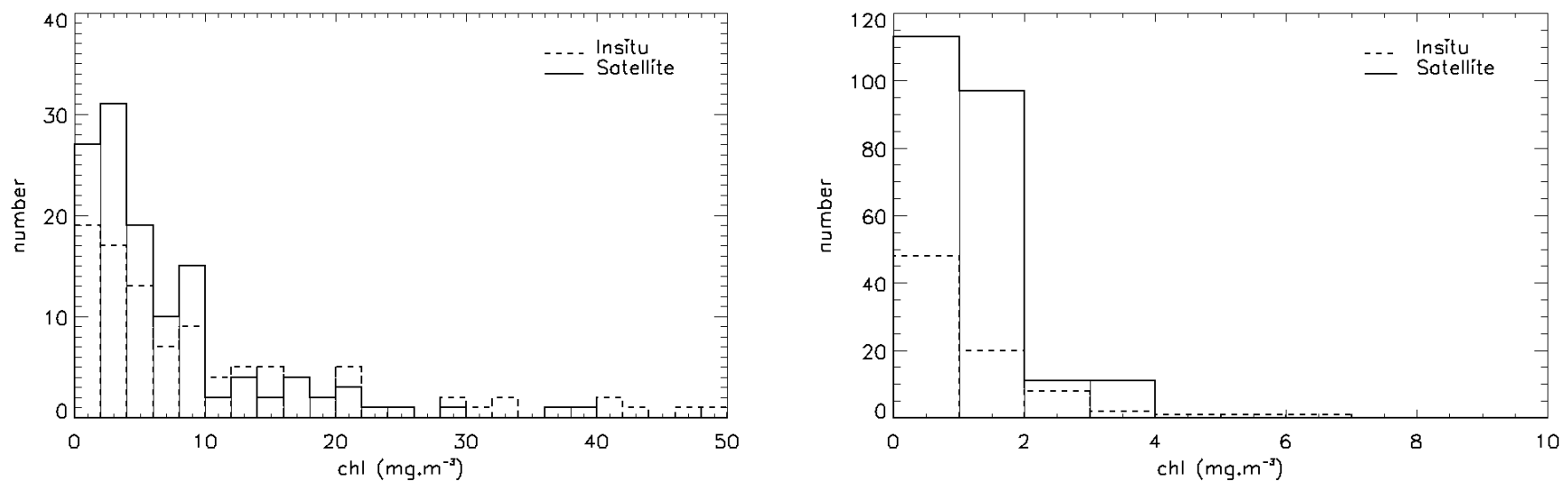

\subsection{The satellite P90 in the vicinity of the selected stations}

The comparisons of the satellite and in situ seasonal curves showed strong similarities in their shapes and levels, even if a slight shift in the pixel location is applied. We also observed that the quality of the correlation, i.e. the quality of the satellite estimation, decreases with the distance to the coast. This notion of sensitivity to the coast can not be uniformly defined. It has to take into account the satellite uncertainty, varying with the local conditions (e.g. atmosphere, bathymetry), and the shoreward chlorophyll-a gradient. Nevertheless, the satellite uncertainty can be approached by the percentage of failures occurring in the quality flagging procedure of SeaDAS. The total number of clear radiance available from our satellite archive is $200-250$ for offshore pixels during the productive periods between 1998 and 2004 (see values indicated on Fig. 3e and 4c for the offshore locations of Boulogne Point 3 and Ouest Loscolo). A number of retrievals for the satellite radiance at a given pixel under 100 means that the relative frequency of observation by satellite is less than $50 \%$. This value of 100 observations is chosen as a threshold above which the time series of the satellite chlorophyll-a concentration can safely be used to calculate the average P90. Fig. 7 presents the P90 maps in the vicinity of the selected stations in the northern region. The near shore pixels, where the number of available points to calculate the P90 is less than 100, are shown in white. The triangles along the shore show the in situ P90 calculated at stations where the number of data collected is greater than 40 .

The colour scale of Fig. 7, which is a gradation of blue, green, yellow, orange and red tinges, encompasses the five classes of quality status of the WFD and their associated colour code (blue for high, green for good, yellow for moderate, orange for poor and red for bad). In the vicinity of the stations of high chlorophyll-a concentration, located near Boulogne, Cabourg and Ouest Loscolo, the satellite P90 is slightly lower. As already mentioned, the difference between the satellite and in situ P90 at these locations can partly be explained by a chlorophyll-a underestimation by the LUT in turbid waters, the proximity of the in situ stations to the coast, and the support effect. 

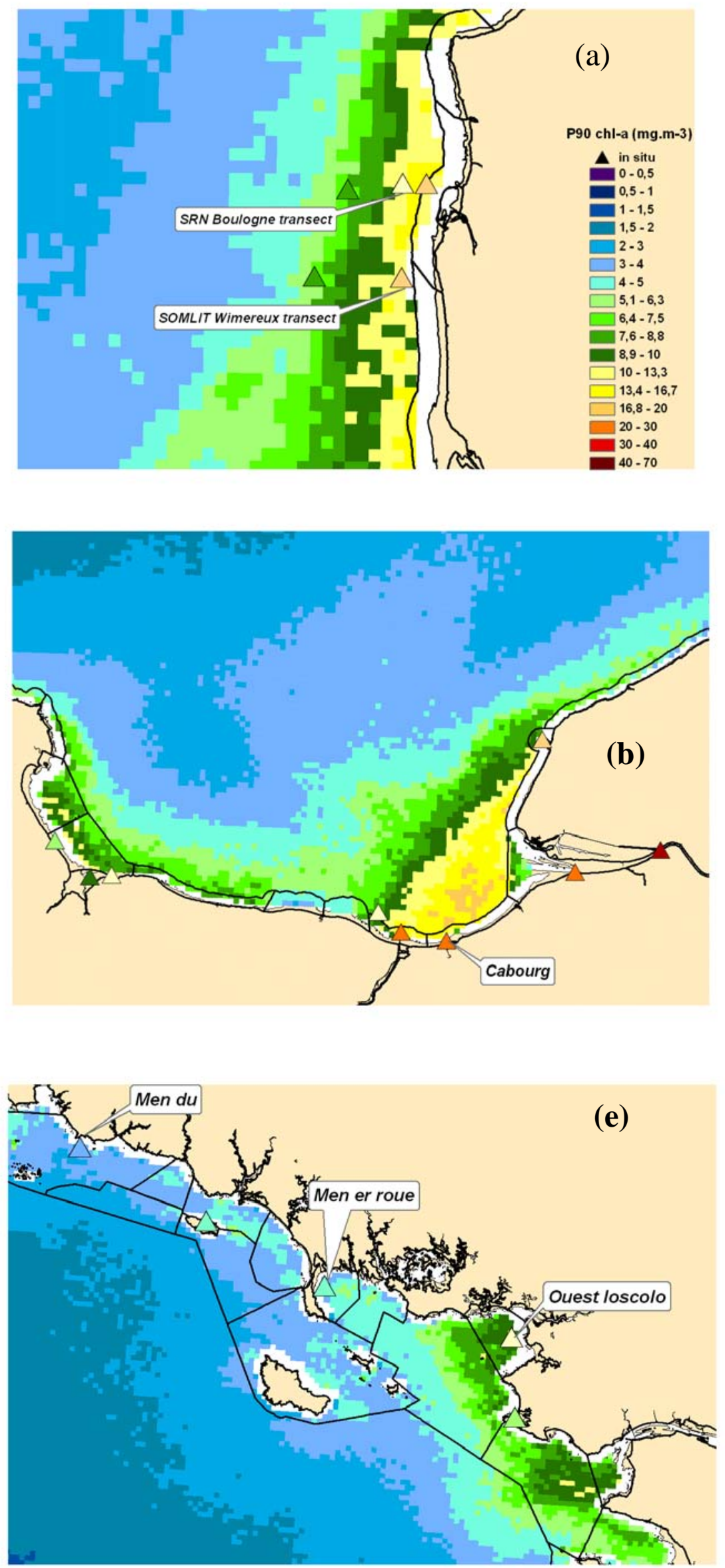
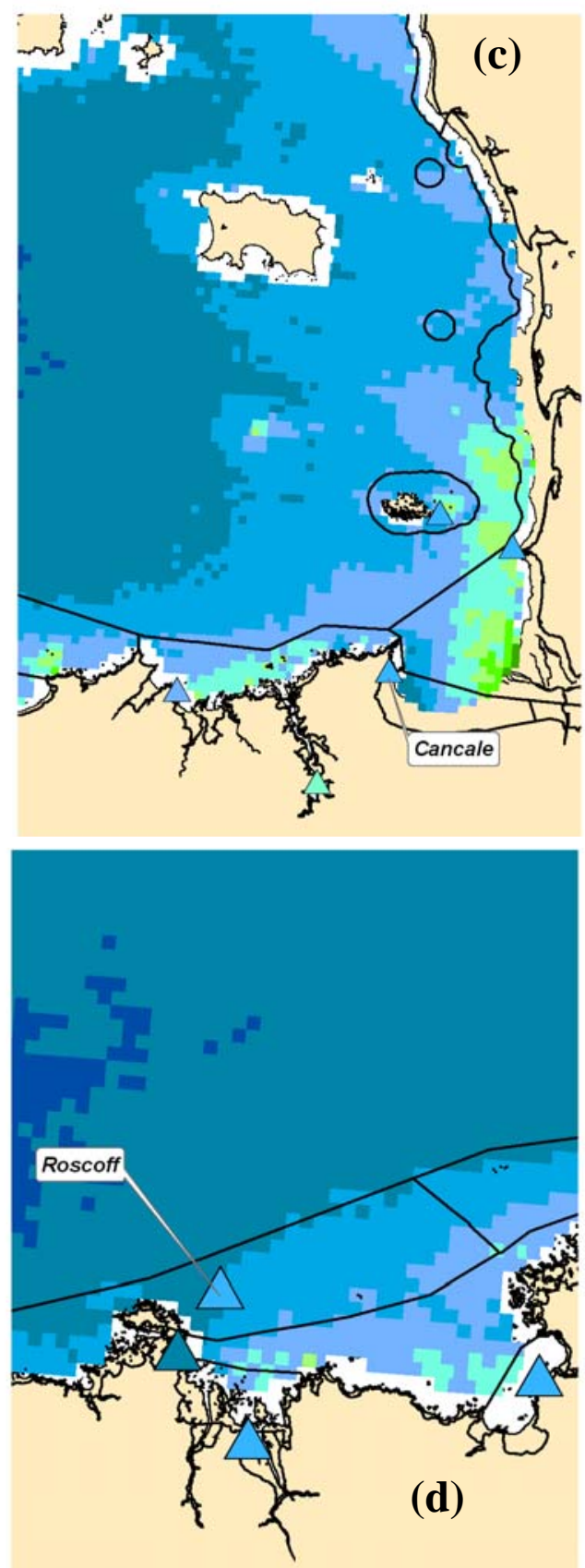

Fig.7. P90 of chl-a in the vicinity of the northern stations

P90 are indicated when calculated from a minimum of 100 (satellite) or 40 (in situ) retrievals. White areas are not estimated.

The colour scale, with blue, green, yellow, orange and red nuances, encompasses the 5 classes of quality status and their colour code (blue for very good, green for good, ...) 

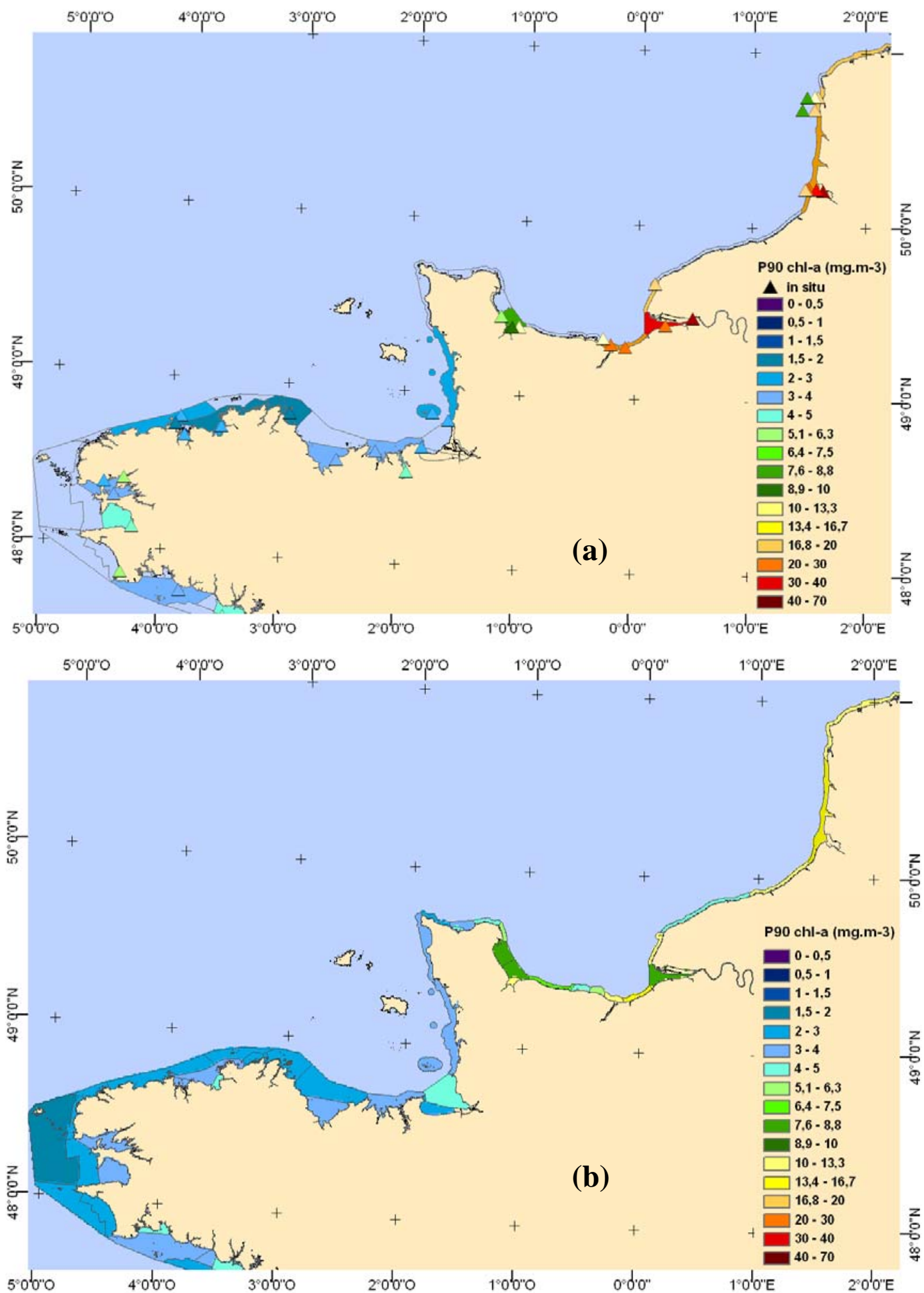

Fig.8. Mean P90 of chl-a for the English Channel water bodies

(a) Classification from in situ data averaged on the water bodies. Triangles indicate the station.

(b) Classification from satellite data averaged on the water bodies.

$P 90$ are indicated when calculated from a minimum of 100 (satellite) or 40 (in situ) retrievals 


\subsection{The in situ and satellite classification}

Fig. 8a shows the classification of the water bodies deduced from the in situ P90 for the English Channel stations. Many water bodies cannot be classified because the available data are too scarce. Fig. $8 \mathrm{~b}$ presents the final classification using the satellite-derived P90 integrated over the water bodies. Fig. 9, with a zoom on the Boyard station, and Fig.10 show the maps obtained for the Bay of Biscay. At first glance, the satellite and in situ classifications show much similarity. Two water bodies coloured in red on the in situ maps (Fig. 8.a), located in the estuaries of the Seine and Somme rivers, are transitional waters and are not directly concerned by this study. In these estuarine areas, it is mainly freshwater chlorophyll-a that has been observed by the RNO network. The satellite P90 shows a steep chlorophyll-a gradient at the western boundary of the Seine transitional water body (Fig. 7b). This line draws the chlorophyll-a front separating the offshore nutrient-rich and relatively clear waters of the outer plume from the turbid transitional waters of the inner plume of the river Seine. Fig. 11 shows the mean satellite versus the mean in situ P90 for each water body showing at least one station sufficiently sampled (40 measurements). On that plot, the highest in situ P90-ch corresponds to the Cabourg water body. At Cabourg and for other near shore water bodies, mainly located in the northern area, a low frequency of satellite observations could lead to a negative bias in P90 as the highest coastal chlorophyll-a concentration may not be observed.

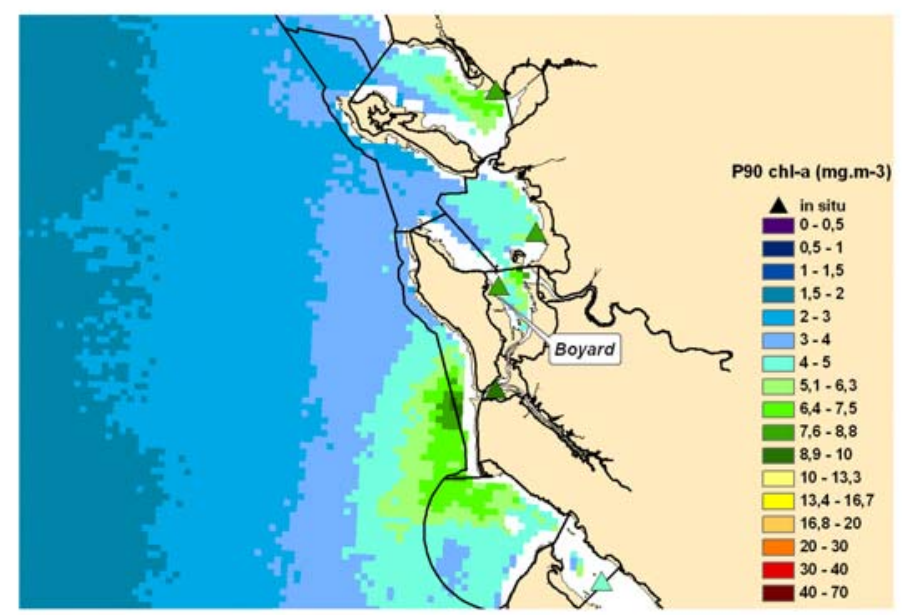

Fig.9. P90 of chlorophyll-a in the vicinity of the southern stations

P90 are shown when they are calculated with a minimum of 100 occurrences for the satellite and 40 for in situ. Grey areas are not estimated 


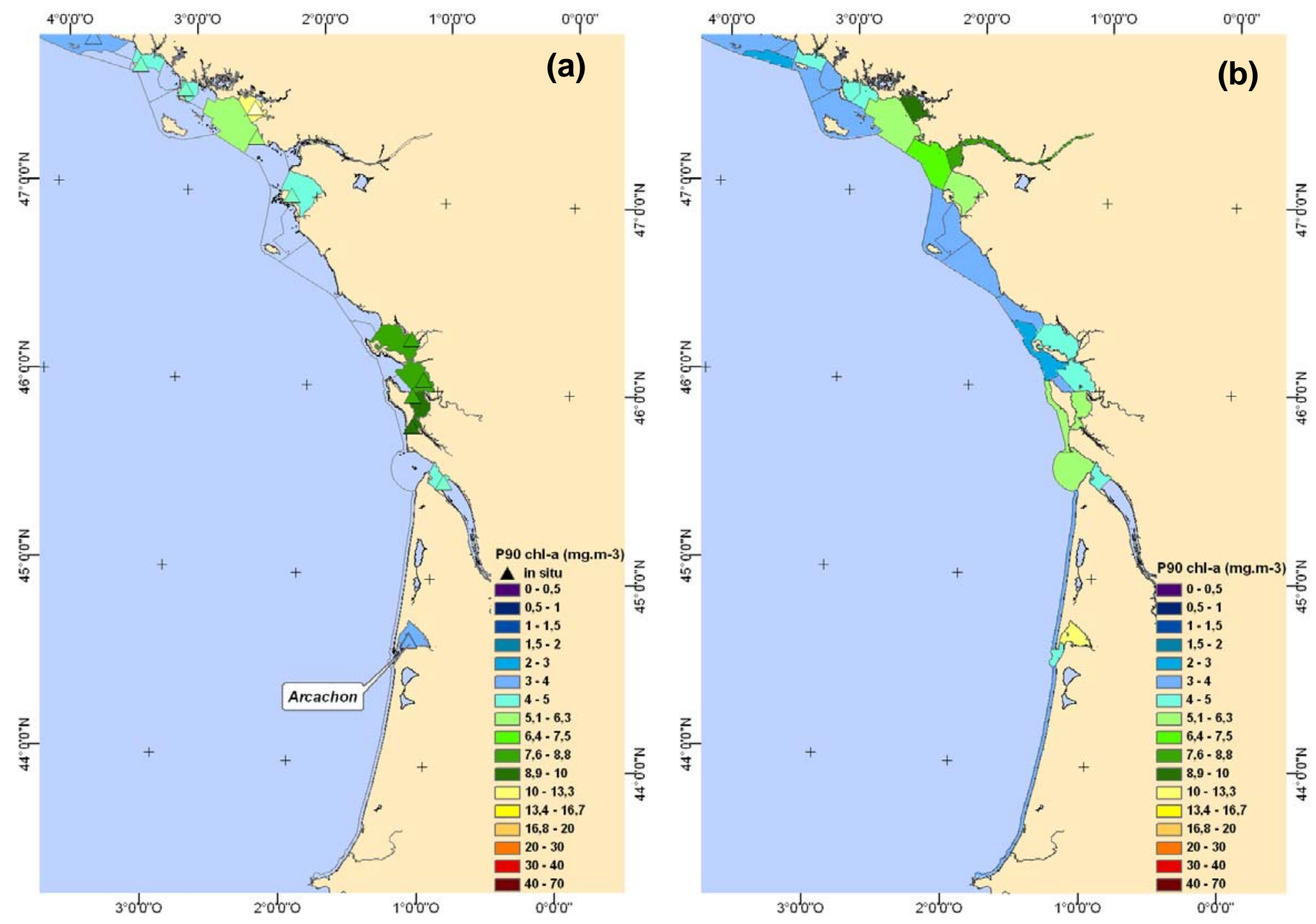

Fig.10. Mean P90 of chl-a for the Bay of Biscay water bodies

(a) Classification from in situ data averaged on the water bodies.

(b) Classification from satellite data averaged on the water bodies.

P90 are shown when calculated from a minimum of 100 (satellite) or 40 (in situ) retrievals

From our data set, composed of seven coastal stations and one transect, similar seasonal curves of P90 are observed whatever the origin of the data. We defined a shift for all those stations, except for Roscoff-Astan, enabling the creation of satellite and in situ time series. Other stations could have been selected as the number of stations sufficiently sampled is about twenty along the shores of the Bay of Biscay and the English Channel. All these time series (not shown) are in good correspondence, except at one point (Teychan bis), located in the Bassin d'Arcachon, where the satellite curve is significantly higher than its in situ equivalent. This results in a degradation of the quality status of the Bassin d'Arcachon when the water body is classified from satellite data (see Figs. 10a and 10b). More attention will be paid to this location to investigate the particular conditions which can cause this deviation. Fig.s of the in situ and satellite P90 (Figs 7. and 9) show that the locations of the in situ stations are not always representative of their respective water body. On Fig. 7c, P90 at Cancale is lower than the mean P90 of its water body. This shows a clear increasing gradient of chlorophyll-a eastwards, which is probably linked to riverine inputs in the eastern part of the bay of Mont-Saint Michel. Conversely, the P90 at Ouest-Loscolo is among the highest in its water body as the chlorophyll-a gradient increases shoreward (Fig. $7 \mathrm{e})$. In the wide water bodies around Brittany and the islands in general, a more realistic classification is obtained using satellite-derived chlorophyll-a than in situ measurements which are sometimes missing or located at the boundary of water bodies. The situation is different for the narrow water bodies along shores of the northern Channel for which there is a negative bias when the estimation is derived from satellite data. It clearly 
appears on Fig.11 that satellite imagery gives a higher classification of the ecological status than in situ data for the most productive water bodies. We have already identified the main causes of potential underestimation of P90 by the satellite method. If the whole water body is now considered instead of a single pixel or location, using only near shore in situ data generally cause an overestimation of the average P90 as these stations often correspond to the highest level of chlorophyll-a . As a result, the underestimation by the satellite, as observed on point-to-point comparisons, and the overestimation by the in situ sampling tend to increase the difference between both classifications on many water bodies. If the SeaWiFS sensor may encounter difficulties to monitor effectively the near shore pixels, it is important to note that the coastal in situ sampling might also misrepresent the whole water body, particularly where this latter is wide or long.

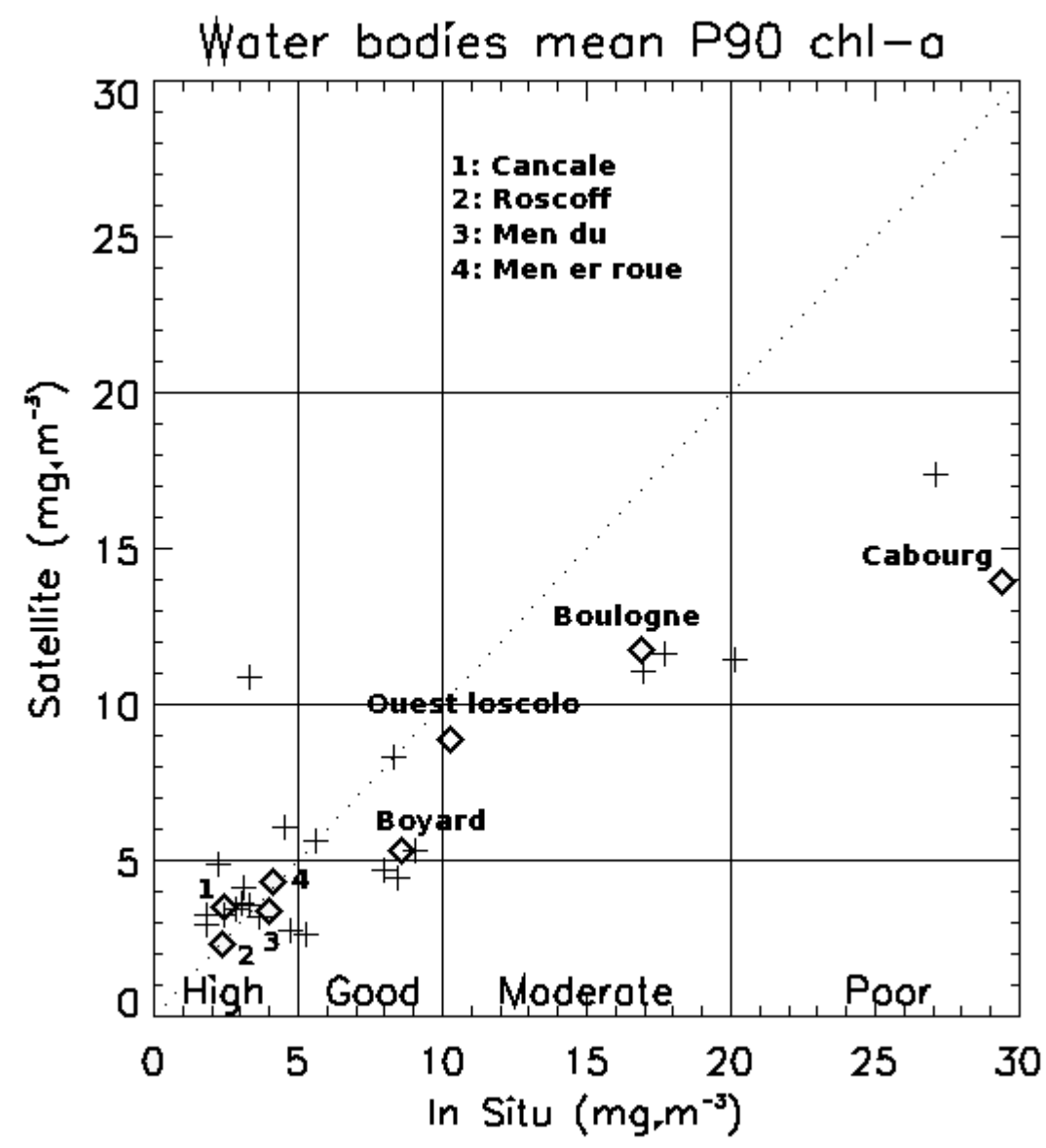

Fig.11. Satellite versus in situ P90 averaged over the water bodies (excluding the transitional water bodies) . Diamond indicate water bodies corresponding to the stations mentioned in this study

P90 are indicated when calculated from a minimum of 100 (satellite) or 40 (in situ) retrievals 


\section{Conclusion}

After observing very similar patterns in the chlorophyll-a cycle whatever the origin of the estimation at selected stations, we proposed a classification of coastal water bodies based on satellite data. However, we observed a significant difference between the field and satellite-derived histograms that may lead to a switch to a less favourable class when the classification is made from in situ measurements. Nevertheless, the origin of this deviation was not clearly identified and can be due to the coastal gradient, the support effect, the microstructures at the scale of the pixel size and approximations in the methods. Although the remote sensing technique can fail or give doubtful results in some very narrow water bodies subject to a strong chlorophyll-a gradient, as in the Northern English Channel, in most of the situations the satellite-derived classification is very realistic. The remote sensing method is particularly suited for the largest water bodies, such as those surrounding islands, where several stations are needed to ensure a reliable in situ monitoring. In case water bodies need a densification of the in situ network to comply with the requirement of the Water Framework Directory, this study can help to optimise the location of new stations. Nevertheless, the in situ network cannot be redesigned each time a new policy is decided as long term in situ monitoring at given stations provides irreplaceable sources of data. Numerous environmental parameters cannot be assessed from space (phytoplankton community structure, $\mathrm{O}_{2}$, etc.) and other considerations than the biomass estimation are taken into account for the design of an in situ monitoring network. However, it is clear that the satellite data are able to efficiently extend the networks to comply with the new surveillance policy at reasonable cost. Optimising the networks allows a better monitoring of the whole area and leads to a better efficiency and motivation of the people involved, as all the sources of data are fully used. For that reason, this work has initiated fruitful exchanges between the field and remote sensing scientific communities. The specific monitoring requirements of the WFD have encouraged an interdisciplinary work which appeared to be a necessity to achieve its goal. The dynamics now in place will certainly lead far beyond the first aims of the WFD and pave the way to the GMES program of the European Union. The spatial extension of monitoring enabled by remote sensing will also create a monitoring system able to meet the requirements of the forthcoming European Maritime Strategy (EMS) Directive. EMS considers a much wider maritime area than the WFD, putting forward the need for remote sensing data. Other issues than the eutrophication risk also have to be addressed in the management of coastal waters. These very productive waters are intensively used for shellfish farming. Shellfish can be affected by eutrophication through hypoxia or the growth of toxic phytoplankton species, but a high phytoplankton biomass is a positive factor which enhances their growth and production. Thus, there could be a potential conflict between different policies aiming at mitigating the eutrophication risk and developing shellfish farming. It is the whole food web that should be considered in an integrated management strategy of the coastal waters, with all its components including fish stocks.

Although it was not described here, MODIS and MERIS sensors can also be used to update each year the WFD classification. MERIS can be processed at raw resolution, equivalent to MODIS and SeaWiFS, but also at full resolution, allowing a $250 * 250 \mathrm{~m}^{2}$ pixel size particularly suited for coastal issues. Moreover, satellite sensors can provide data concerning other parameters required by the WFD such as temperature, turbidity and suspended matters. Together with the in situ data, this new approach using remote sensing will contribute to assess the efficiency of water policies through the observation of the inter-annual variability and trends in phytoplankton biomass. 


\section{References}

Druon, J.N., Loyer, S., \& Gohin, F. (2005). Scaling of coastal phytoplankton features by optical remote sensors: comparison with a regional ecosystem model. International Journal of Remote Sensing, 26, 4421-4444.

European Commission, Directive 2000/60/EC of the European Parliament and of the Council of 23rd October 2000 establishing a framework for Community action in the field of water policy (2000). Official Journal 22 December 2000 L 327/1, Brussels: European Commission.

European Communities (2005) Common implementation strategy for the Water Framework Directive (2000/60/EC) Guidance Document No. 14 Luxembourg: Office for Official Publications of the European Communities. ISBN 92-894-9471-9.

Fisson, C. \& Belin, C. (2005). Indicateur de biomasse : chlorophylle a. Simulation de classement des masses d'eau DCE. Rapport Ifremer, DYNECO/VIGIES, 9 p.

Fu, G., Baith, K. S., \& McClain, C. R. (1998). SeaDAS: The SeaWiFS data analysis system. Proceedings of the 4th Paci. c Ocean Remote Sensing Conference, Qingdao, China, 28-31 July, edited by Ming-Xia He and Ge Chen (Beijing: Beijing Fortune Quick Printing Corporation), pp. 73-77.

Gohin F., Druon J.N. \& Lampert, L. (2002). A five channel chlorophyll algorithm applied to SeaWiFS data processed by SeaDAS in coastal waters. International Journal of Remote Sensing, 23, 1639-1661.

Gohin, F., Lampert, L., Guillaud, J.F., Herbland, A., \& Nézan, E. (2003). Satellite and in situ observations of a late winter phytoplankton bloom in the northern Bay of Biscay. Continental Shelf Research, 23, 1117-1141.

Gohin F., Loyer S., Lunven M., Labry C., Froidefond J.M., Delmas D., Huret M. \& Herbland A. (2005). Satellitederived parameters for biological modelling in coastal waters: Illustration over the eastern continental shelf of the Bay of Biscay. Remote Sensing of Environment, volume 95, Issue 1, 29-46.

Huret M., Gohin F., Delmas D., Lunven M., Garçon V. (2007). Use of SeaWiFS data for light availability and parameter estimation of a phytoplankton production model of the Bay of Biscay. Journal of Marine Systems, 65, 509-531.

Lacroix G., Ruddick K., Park Y., Gypens N., \& Lancelot, C. (2007). Validation of the 3D biogeochemical model MIRO\&CO with field nutrient and phytoplankton data and MERIS-derived surface chlorophyll a images. Journal of $\begin{array}{lllll}\text { Marine } & \text { Systems, Volume } & 64, & \text { Issues } & 1-4, \text { Pages }\end{array}$

Lajaunie, C. \&Wackernagel, H. (2000). Geostatistical Approaches to Change of Support Problems - Theoretical Framework - Report No 19 of Contract IST Impact-1999-11313. Technical Report N-30/01/G of the ENSMP, Centre de Géostatistique.

Lazure, P., Mauge, R., Erhold, A., Guillaumont, B., Croguennoc, C., Raffin, B., Beliaeff, B. \& Joanny, M. (2002). Mise en œuvre de la Directive Cadre sur l'Eau. Propositions Ifremer pour une typologie des eaux côtières et de transition. Rapport Ifremer, DEL/AO, $20 \mathrm{p}$.

Lorenzen, C., J. (1967). Determination of chlorophyll and pheophytin: spectrophotometric equations. Limnol. Oceanogr.

Ménesguen A. \& Gohin, F. (2006).Observation and modelling of natural retention structures in the English Channel. Journal of Marine Systems, Vol. 63, Issue 3-4, 244-256.

Ménesguen, A., Cugier, P., Loyer, S., Vanhoutte-Brunier A., Hoch, T., Guillaud, J.F., \& Gohin, F. (2007). Two- or three-layered box-models versus fine 3D models for coastal ecological modelling? A comparative study in the English Channel (Western Europe). Journal of Marine Systems, 64, 47-65.

Miller, P., Shutler, J., Moore, G., \& Groom, S. (2006). SeaWiFS discrimination of harmful algal bloom evolution, International Journal of Remote Sensing 27, 2287-2301 
Neveux, J. (1976). Dosage de la chlorophylle-a et de la phéophytine a par fluorimétrie. Ann. Inst. Océanogr. 52, 165-174.

Nixon, S.W. (1995). Coastal marine eutrophication: a definition, social causes, and future concerns. Ophelia, 41, 199-219

O'Reilly, J.E., Maritorena, S., Mitchell, B.G., Siegel, D.A., Carder, K.L., Garver, S.A., Kahru, M., \& McClain, C. (1998). Ocean color chlorophyll algorithms for SeaWiFS. Journal of Geophysical Research, 103, 24937-24953.

Smyth, T. J., Moore, G. F., Groom, S. B., Land, P. E., \& Tyrrell, T. (2002). Optical Modeling and Measurements of a Coccolithophore Bloom. Applied Optics 41, 7679-7688

Wozniak, S.B. \& Stramski, D. (2004). Modeling the optical properties suspended in seawater and their influence on ocean reflectance and chlorophyll estimation from remote sensing algorithms. Applied Optics, 43, 3489-3503.

\section{Acknowledgments}

The authors would like to thank the SeaWiFS Project and the Distributed Active Archive Center at the Goddard Space Flight Center, Greenbelt, MD 20771, for the production and distribution of the SeaWiFS data acquired at the Dundee station. We are also indebted to NASA for providing the SeaDAS software. We are extremely grateful to all who provided the field measurements and to all who have contributed to the numerous field measurements, particularly through the REPHY/Ifremer and SOMLIT/CNRS-INSU networks. We also thank Philippe Fera of the Water Agency Loire-Bretagne for his support. Thanks also to the referees, and Jean-Noel Druon for their helpful comments on the manuscript. This work has been partly funded by the MarCoast project, a GMES Service Element funded by ESA (European Space Agency) and the Agence de l'Eau Loire-Bretagne. The SRN network was partly funded by the Agence de l'Eau Artois Picardie, and the RHLN network by the Agence de l'Eau Seine-Normandie. 